\section{EMBRYRIDDLE Aeronautical University}

SCHOLARLY COMMONS
International Journal of Aviation, Aeronautics, and Aerospace

\title{
Pilot Visual Detection of Small Unmanned Aircraft on Final Approach during Nighttime Conditions
}

Jon M. Loffi

Oklahoma State University - Main Campus, jon.loffi@okstate.edu

Ryan J. Wallace

Embry-Riddle Aeronautical University, ryan.wallace@erau.edu

Samuel M. Vance

Oklahoma State University - Main Campus, matt.vance@okstate.edu

Jamey Jacob

Oklahoma State University - Main Campus, jdjacob@okstate.edu

Jared C. Dunlap

Oklahoma State University - Main Campus, jared.dunlap@okstate.edu

Taylor A. Mitchell

Oklahoma State University, taylor.mitchell@okstate.edu

Dane C. Johnson

Oklahoma State University, dane.johnson@okstate.edu

Follow this and additional works at: https://commons.erau.edu/ijaaa

Part of the Aviation Safety and Security Commons

\section{Scholarly Commons Citation}

Loffi, J. M., Wallace, R. J., Vance, S. M., Jacob, J., Dunlap, J. C., Mitchell, T. A., \& Johnson, D. C. (2021).

Pilot Visual Detection of Small Unmanned Aircraft on Final Approach during Nighttime Conditions. International Journal of Aviation, Aeronautics, and Aerospace, 8(1). https://doi.org/10.15394/ ijaaa.2021.1568

This Article is brought to you for free and open access by the Journals at Scholarly Commons. It has been accepted for inclusion in International Journal of Aviation, Aeronautics, and Aerospace by an authorized administrator of Scholarly Commons. For more information, please contact commons@erau.edu. 
On the evening of January 22, 2019, pilots for both Southwest Airlines and United Airlines reported encountering a drone flying at 3,600 feet while on final approach to Newark Airport, New Jersey (Aratani, 2019; Law, 2019). An exchange between the air traffic controller and Southwest Airlines pilot highlighted the incident (LiveATC, 2019):

SWA Pilot: 'Be advised there's something on final here we don't, we thought maybe it was a drone, uh, but there's, uh, definitely, uh something on final here."

Controller: “. . And you say something on final, I'm not sure what you mean. Like an object or something?"

SWA Pilot: $\quad$ Yes sir, an object and it definitely looks like a drone.

Controller: "OK, altitude?"

SWA Pilot: "We just passed it, so thirty- ... call it thirty-six hundred feet."

Operations at Newark were briefly suspended, resulting in 43 flights being diverted to other airports (Shepardson, 2019). Similar situations have been encountered at multiple airports both in the United States and abroad. Pilot encounters with unmanned aircraft continue to remain problematic. As of the end of 2019, the FAA had received 9,596 reports of pilot encounters or other airspace hazards associated with unmanned aircraft since the agency first started recording UAS issues in November 2014 (FAA, 2020c).

\section{Problem}

In December 2020, the Federal Aviation Administration announced a new final rule that permits routine small UAS night operations, provided operators complete a knowledge test highlighting the risks and mitigation strategies for nighttime flight and equip their UAS with anti-collision lighting that is visible for at least 3 statute miles with a sufficient flash rate to avoid a collision (Operation of Small Unmanned Aircraft Systems Over People, 2021). Contained in the Operation of Small Unmanned Aircraft Systems Over People (2021) Final Rulemaking, public comment indicated possible safety concerns including:

- "... whether the FAA had adequately evaluated available sightings data and confirmed its reliability for as its basis for expanding small UAS operations at night" (p. 4354).

- "Pilot difficulty spotting a sUAS while the pilot is operating at low altitude in a high-task load environment; and, pilots may experience difficulty identifying small UAS at night" (p. 4354). 
- ". . . concern about the risk small unmanned aircraft pose for commercial aircraft.” (p. 4354).

These concerns formed the basis of this research project.

\section{Significance of the Problem}

Of the 9,596 UAS Sighting Reports recorded by the FAA, at least 826 $(8.61 \%)$ were conducted outside of daylight hours (see Figure 1). Of those, 64 $(.667 \%)$ sightings occurred prior to the start of morning civil twilight; $19(.197 \%)$ occurred during either morning or evening civil twilight; and, 762 (7.94\%) occurred after evening civil twilight (see Figure 2).

\section{Figure 1}

UAS Sighting Reports by Month with Proportion Conducted Outside Civil

Twilight Hours (Nov 2014-Dec 2019)

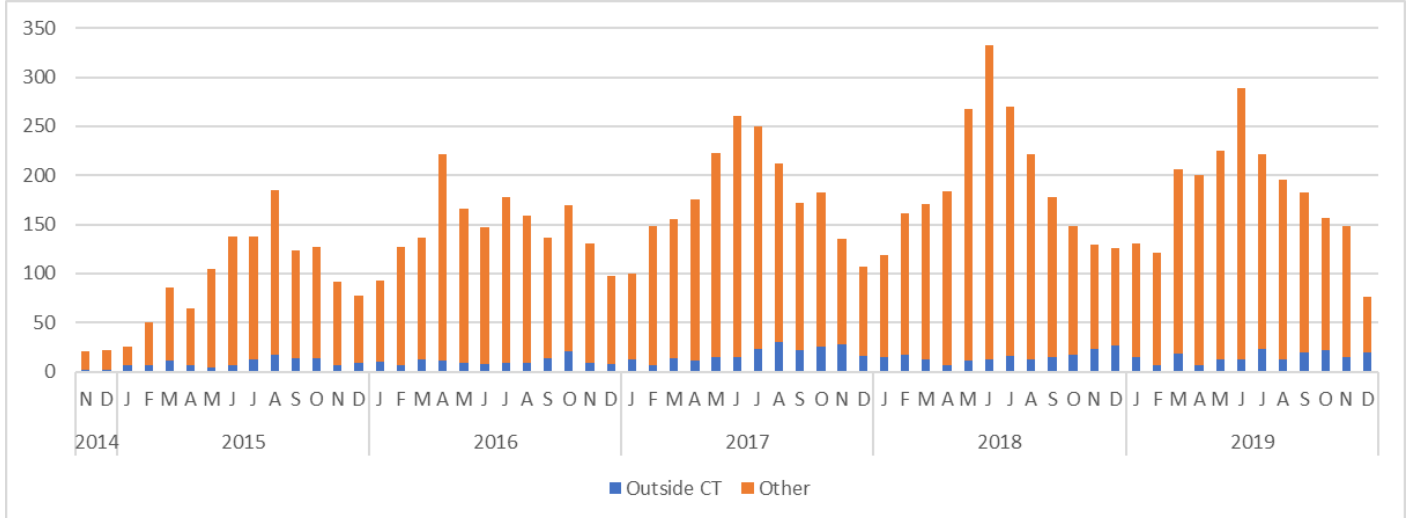


Figure 2

UAS Sightings Reports by Local Time of Day (Nov 2014-Dec 2019)

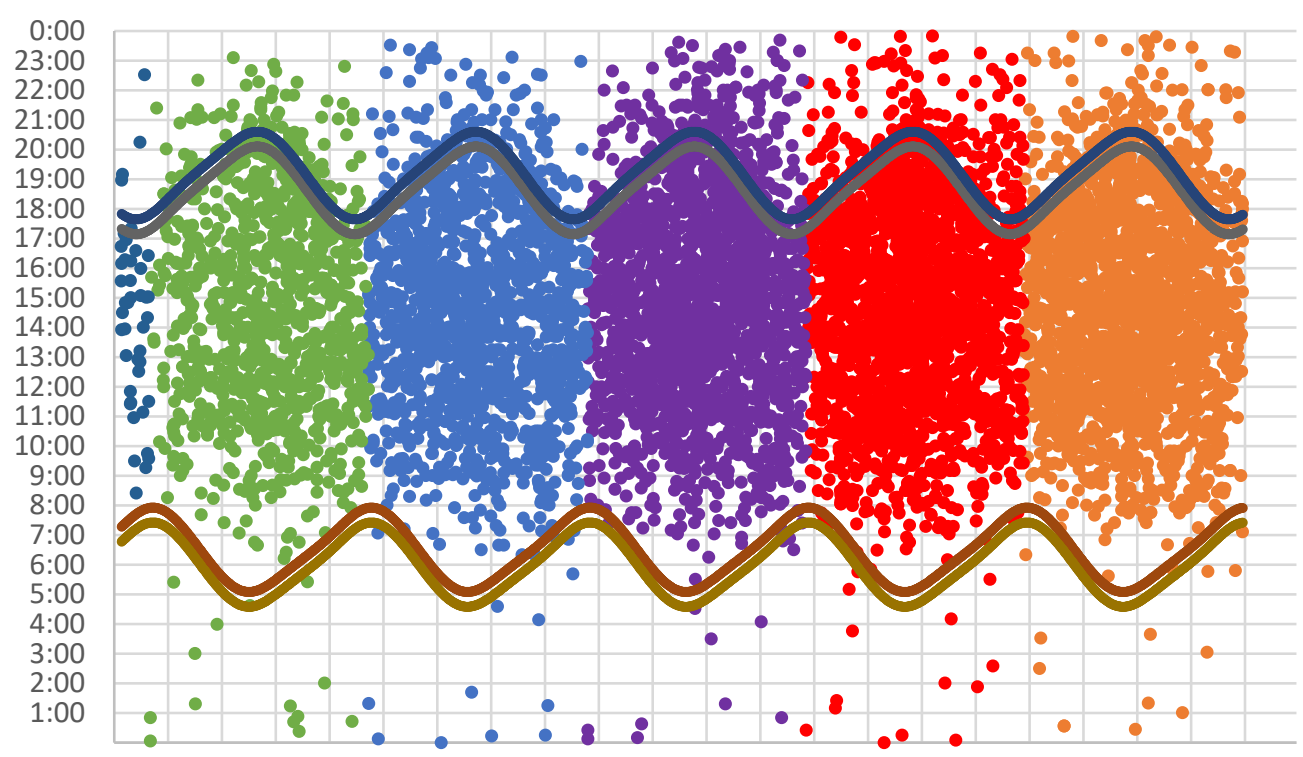

N-14J-15A-15J-150-15J-16A-16J-160-16J-17A-17J-170-17J-18A-18J-180-18J-19A-19J-190-19J-20

Note: Excludes airspace alerts/reports in Zulu Time. Overlaid with estimated sunrise / sunset / civil twilight times, based on geographical center of Continental U.S. Data derived from UAS Sighting Reports database (FAA, 2020c).

\section{Purpose}

This research represents the fourth study in a series of experimental research projects designed to assess pilot visual detection and collision avoidance of small unmanned aircraft systems. The purpose of this study was to evaluate the effectiveness of in-flight pilot visual detection of small UAS platforms encountered during nighttime, visual meteorological conditions (VMC) during the approach to landing phase of flight. The research team wanted to assess if strobeequipped small UAS flying near an airport approach path could be readily spotted and visually distinguished from airport approach lighting systems; and subsequently, if a pilot could evade a potential midair collision.

\section{Research Questions}

Researchers sought to answer the following research questions:

- What is the visual detection rate for a small unmanned aircraft system by an aware pilot during nighttime conditions while on a visual approach to an airport with approach lights? 
- Is pilot visual detection for a small unmanned aircraft system adversely affected by airport approach lighting systems?

- Is a pilot likely to be able to evade a small unmanned aircraft encountered on approach to an airport during nighttime conditions?

\section{Literature Review}

The following prior studies provide input to the challenges associated with pilot detection of small unmanned aircraft systems at night.

Williams and Gildea (2014) identified eight factors that complicate visual detection to potential collision threats, including:

- Small Visual Angle: the small visual angle between the observer and target object prevent recognition of the object until it becomes large enough to be conspicuous.

- Cockpit Obstructions: detecting airborne collision threats in the cockpit environment is complicated by the aircraft structure, passengers, glare, or other factors which may obstruct or otherwise hinder effective visual scanning.

- Visual Acuity: physiological limitations such as the foveal visual field, observer age, fatigue, light/dark adaptation, and hypoxia can potentially impact visual focus.

- Visual Accommodation: focusing on distant objects can be complicated by the natural tendency for humans to focus at close distances in the absence of visual cues, a condition known as empty field myopia.

- Poor Contrast: visibility of an object is improved with increased contrast, or the difference in luminance between the target object and the background.

- Complex Backgrounds: occurs when the background behind an object contains varied lighting levels, making it difficult to discern the object

- Lack of Apparent Motion: human vision is adept at identifying relative motion. On a collision course, most relative motion cues are limited.

- Visual Search Requirements: cockpit distractions and other tasks complete for a pilot's attention. Workload management and distractions limit pilot scanning to approximately one third of available time.

According to the FAA (2016a),

Nighttime operations pose a higher safety risk because the reduced visibility makes it more difficult for the person maintaining visual line of sight to see the location of other aircraft. While the existence of other 
lighted manned aircraft may be apparent due to their lighting, the distance and movement of small unmanned aircraft relative to the distance and movement of those aircraft is often difficult to judge due to the relative size of the aircraft. In addition, visual autokinesis (the apparent movement of a lighted object) may occur when the person maintaining visual line of sight stares at a single light source for several seconds on a dark night. For this reason, darkness makes it more difficult for that person to perceive reference points that could be used to help understand the position and movement of the lighted manned aircraft, the small unmanned aircraft, or other lighted object. (p. 162)

The FAA (2016a) highlighted the challenges in determining the precise location of a small UAS at night without supplemental equipment. The reliance on human vision to assess flight characteristics is likely to be compromised during nighttime conditions in the absence of contextual reference points (FAA, 2016a). According to the FAA (2016a), the aforementioned factors significantly increase the potential risk of a midair collision between a small UAS and manned aircraft.

\section{United States Air Force (USAF) Lighting Studies}

In a test of the effectiveness of aircraft anti-collision lighting systems, the United States Air Force conducted a series of tests to evaluate the detectability of various strobe lighting configurations. The USAF studies attempted to model the factors affecting the probability of detection and reaction time for an aircraft, using the following variables: Lights, Visibility, Background Luminance, Range, and Eye (Retinal) Location (USAF, 1976). Researchers determined that testing showed strobe lighting demonstrated limited viability in enhancing visual detection during daylight hours, due in large part to high levels of background illumination (USAF, 1976). During nighttime testing, however, main effects were found be to be significant for all but the visibility variable. This indicates that strobe lightings systems were effective at lower levels of background luminance, such as those encountered in dark, nighttime conditions (USAF, 1976).

\section{Nighttime Small UAS Visibility Studies}

Static UAS Nighttime Visibility Testing. In a study by Stevenson, O'Young, and Rolland (2015) at an abandoned U.S. Naval Air Station in Newfoundland, researchers equipped a small unmanned aircraft with wingtip navigation lights and strobe lighting, and affixed it to a movable test stand. Thirteen participants were individually brought inside the darkened cab of a recreational vehicle $(\mathrm{RV})$, simulating an aircraft cockpit. The small UAS was illuminated and subjects were asked to discern the orientation of the small UAS, based on eight different lateral orientations using only the navigation lighting. The experiment was repeated with the RV relocated to three different observation 
points at $500 \mathrm{~m}, 1,000 \mathrm{~m}$, and $1,609 \mathrm{~m}$ from the test stand. The test was repeated using the both the navigation lights and strobe lights. Stevenson et al. (2015) indicated increased accuracy in the participant's determination of orientation when the strobe lights were used. Stevenson et al. (2015) determined that the craft should be hypothetically visible for at least $2.6 \mathrm{~km}$ in nighttime conditions.

Nighttime UAS Visibility Flight Testing. In a field test at Jornada Experimental Range, Dolgov (2016) conducted a series of tests to evaluate visual observer ability to maintain visual contact with a small unmanned aircraft and detect intruding aircraft under various lighting conditions. The visual observers monitored the sky for an intruding aircraft to assess potential collision hazards with either a Raven RQ-11 or Wasp III small unmanned aircraft. The experiment revealed that the time of day did not adversely impact the ability of the visual observers to maintain visual contact with the intruding aircraft, however, tracking the small unmanned aircraft was significantly improved during dusk and nighttime conditions. At night, the visual observers were able to spot the intruding aircraft at $2.09 \mathrm{~km}$; the [larger] Raven RQ-11 UAS at .83km; and, the [smaller] Wasp III at .76 km. According to Dolgov (2016):

The data generated by this study strongly suggest that, under near-optimal viewing conditions, it is easier to detect and track manned and unmanned aircraft at night than during the day. This is consistent with the fact that a point light source has much greater contrast against a dark night sky than an aircraft profile during the day, especially when the sky is overcast. (p. 51)

\section{Daytime UAS Visual Detection Studies}

Additionally, several studies have been conducted that advise about daytime visual detection of small unmanned aircraft. While these studies do not directly address the research questions, they identify unique visibility challenges, as well as provide context to the resulting data.

Ohio University Study. In an Ohio University study by Kephart and Braasch (2010), researchers evaluated in-flight visual detection of large UAS (simulated by a Piper Warrior III) using a camera system, compared to human participants. The research team scripted several conflict encounters and measured the distance the participants were able to visually acquire the conflict aircraft. On average, participants were able to spot the conflict aircraft at an average range of 1.275 SM, with head-on encounters spotted at a mean of 1.038 SM, and intersecting encounters detected at a mean of 1.511 SM.

Colorado Agricultural Aviation Association. In a 2015 study by Maddocks and Griffitt, the Colorado Agricultural Aviation Association conducted a series of in-flight tests designed to locate in-flight UAS or evidence of UAS 
operations by agricultural applicators flying both fixed- and rotary-wing aircraft. Participants conducted an in-flight hazard assessment of five fields to assess for evidence of UAS activity. One field was devoid of hazards, two fields contained marked tarps marked with "UAS" lettering, and two fields contained flying small UAS craft. All five participants noted tarps, but the small UAS was only spotted on three of the available 10 occurrences.

Oklahoma State University Studies. In the first of a series of visibility studies by Loffi, Wallace, Jacob, and Dunlap (2016), researchers performed an inflight experiment with 20 participants to determine the detectability of both a multirotor and fixed-wing UAS under five different encounter conditions. The study revealed relatively marginal levels of detectability for the multirotor small UAS, with an average detection distance of less than .10 statute miles (SM); and, improved detectability of the fixed-wing small UAS at a mean distance of .49 SM (Loffi et al., 2016). In a second in-flight study, Wallace et al. (2016) assessed detectability of multirotor small UAS equipped with strobe lights during daytime conditions. In the Wallace et al. (2016) study, the detection rate for small UAS remained low, with only three detections from a total of 39 possible intercepts. In a final study by Wallace et al. (2019), researchers performed an in-flight test to evaluate pilot visual detection of small UAS during the final approach phase of flight. The small UAS detection rate of the Wallace et al. (2019) study remained reasonably comparable to the initial Loffi et al. (2016) study.

\section{Methodology}

This study employed a mixed-methods approach, with both quantitative and qualitative elements. The research methodology employed was adapted with only minor changes from previous studies conducted by Loffi et al. (2016), Wallace et al. (2018), and Wallace et al. (2019). Sampled participants were purposefully selected from among a population of certificated pilots holding at least a private pilot certificate from a Part 141 collegiate flight training program in the Midwestern U.S. This study was approved by the institutional review board, protocol ED-18-68.

\section{Sampling \& Participant Selection}

Participants were recruited via paper advertisement posted at the institution's flight center one week prior to the experiment. The advertisement contained a brief description of the experiment, overviewed pilot credential requirements, highlighted study benefits, and encouraged prospective participants to signup via email with the principal investigator. The first 10 volunteers were selected for participation in the experiment, with four additional backup participants, in the event of primary participant illness or other issue.

\section{Experiment Location}


The experiment was conducted at Stillwater Regional Airport (SWO), Oklahoma, using Runway 17 (see Figure 3). Stillwater Regional Airport is located on the northwest periphery of the city limits. "The airport averages more than 80,000 aircraft operations annually and is ranked the fourth busiest airport in Oklahoma" (City of Stillwater, 2020, p. 1). As of 2018, the airport was home to 70 based aircraft, including 69 fixed-wing aircraft and one helicopter (City of Stillwater, 2020). The airport maintains air traffic control services from 14000200Z. While the tower is operational, the airport lies in Class D airspace; and, reverts to Class $\mathrm{G}$ airspace outside of service hours (FAA, 2020a).

Runway 17 is configured with Medium Intensity Approach Light System with Runway Alignment Indicator Lights (MALSR). According to the FAA (2020b),

The MALSR, consisting of a combination of threshold lamps, steady burning light bars and flashers, provides visual information to pilots on runway alignment, height precision, roll guidance, and horizontal references for Category I Precision Approaches. A typical MALSR uses 18 lamps (PAR 56) along the runway threshold spaced 10' apart, 9 light bars with 5 lights (PAR 38) separated every 200' and 5 sequenced flashers also separated every 200' over a distance of 2,400' from the runway threshold. At the 1,000' point there are three light bars (15 lamps) for added visual reference for the pilot on final approach. Sequenced flashing lights provide added visual guidance down the runway centerline path. Planned approach visibility is at least $1,800^{\prime}$ to .5 miles, with a decision height of 200'. (p. 1)

Runways 17 was also equipped with 4-light Precision Approach Path Indicator (PAPI) lights on the left side of the runway set for a 3.00-degree glide path. 
Figure 3

Sectional Depiction of Testing Area, Stillwater Regional Airport (SWO), Oklahoma [LEFT]. Excerpt of Stillwater Regional Airport Diagram [RIGHT]

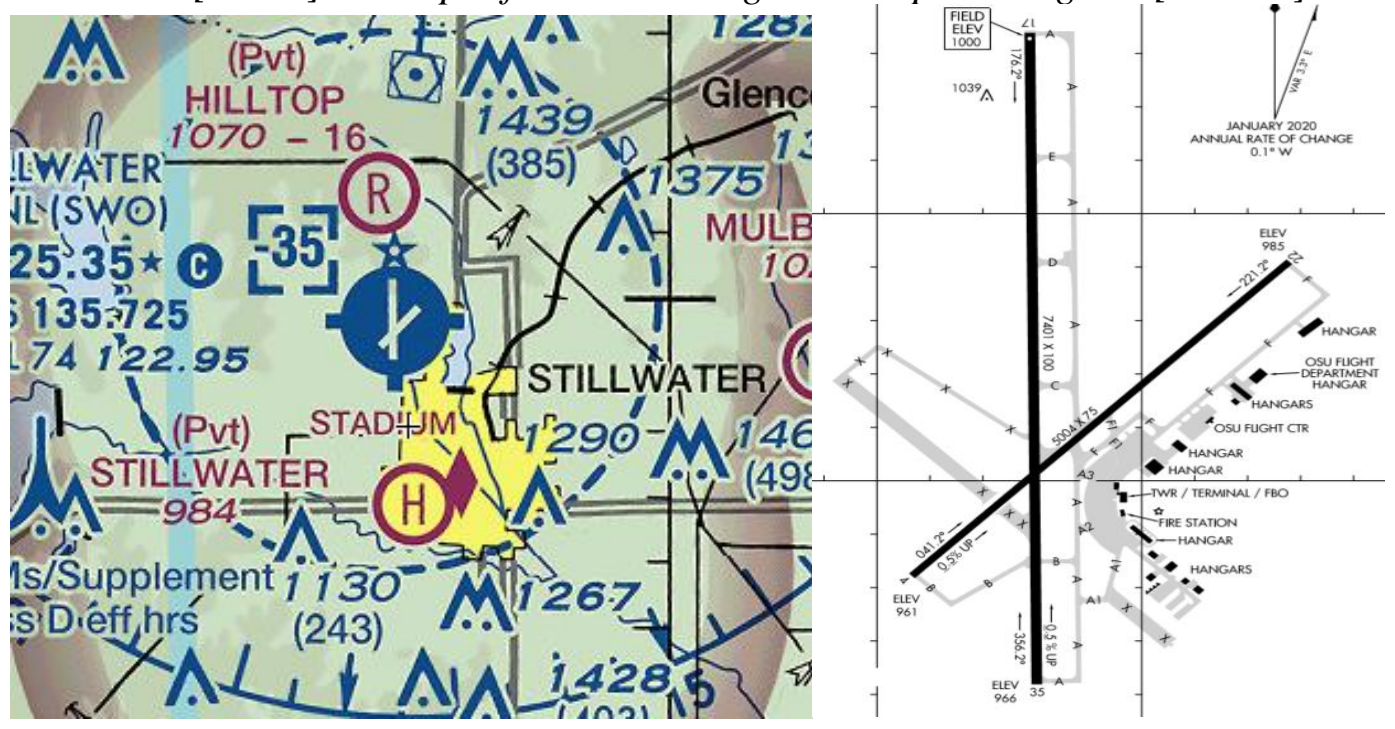

\section{Conditions}

All flights were performed during visual meteorological conditions (VMC) during night, as defined by 14 CFR $\S 1.1$. Flight conditions were reported from historical Automated Surface Observing Systems (ASOS) data derived from the Iowa State University (n.d.) Environmental Mesonet (IEM) records.

\section{Procedure}

Participants performed duties as a pilot in a Cessna C-172/S equipped with a G-1000 avionics package with autopilot functionality. The aircraft was appropriately certified as compliant for Instrument Flight Rules (IFR) flight operations.

Participants were instructed to perform an instrument landing system (ILS) approach to SWO Runway 17, during nighttime conditions. The approach was initiated at $5 \mathrm{NM}$ north of the airfield at 2,700 feet MSL (1,700 feet AGL), with a Decision Height of 1,250 feet MSL (250 feet AGL). The Minimum Safe Altitude (MSA) was also 250 feet AGL.

During each approach a small unmanned aircraft system performed scripted maneuvers on a perpendicular axis at a distance of 1,000 feet from the runway threshold along the approach corridor. All UAS flights were conducted at 42m (approx. 137 feet) AGL. The UAS operations team monitored the aircraft progress along the approach path and executed lateral avoidance maneuvers to ensure the UAS did not actually strike the aircraft. Participants were instructed to initiate a go-around maneuver at Decision Height. Participants were also advised 
they could discontinue the experiment by calling a "knock-it-off" on the radio and executing a go-around maneuver along the runway heading at any time if they felt safety had been compromised.

An Airline Transport Pilot (ATP) with Certified Flight InstructorInstrument (CFII) ratings, served as a safety pilot and accompanied each sortie in the right seat to ensure flight safety was not compromised. Although the participant acted as pilot in command, the safety pilot was prepared to immediately assume control in the event of loss of separation between the aircraft and UAS, or other unanticipated flight hazard.

Before each flight, the principal investigator (PI) provided informed consent to each participant, ensured completion of required IRB documentation, and collected demographic information. The PI also accompanied each flight, stationed in the aft seat of the test aircraft. This individual was responsible for recording participant UAS sighting times, reported verbally on the intercom. Upon conclusion of each successful sighting, the PI would also document any qualitative observations, comments, or impressions, based on the following questions posed to the participant:

- Describe what you saw that allowed you to initially detect the UAV?

- What elements of the UAV were observed?

- How far was the UAV from manned aircraft?

- UAV type/size, maneuver/relative motion, color, lighting, contrast with background

- Was any existing airport lighting confusing?

- What maneuver would be performed to avoid a collision with the UAV?

- General Observations/Remarks

\section{UAS Procedure}

A white DJI Phantom IV (quadrotor UAS) was selected for the experiment. This selection was based on the widespread use of DJI products in the National Airspace System, and the availability of UAS platforms available to the research team. As of 2020, DJI drones represent nearly $77 \%$ of U.S. drones sales - nearly 20 times that of any individual competitor (Schmidt \& Vance, 2020). The UAS was equipped with a Flytron-Strobon Cree white LED light, with a reported visibility of at least 3 miles (see Figure 4). The strobe light was configured for a short-interval pulsing pattern. The research team performed sUAS flights in accordance with a 14 CFR $\$ 107.29$ Daylight Operation waiver \#107W-2019-00505. 


\section{Figure 4}

Flytron-Strobon Cree Standalone Strobe Light [LEFT]. Strobe Mounting on sUAS Dorsal Surface [RIGHT]
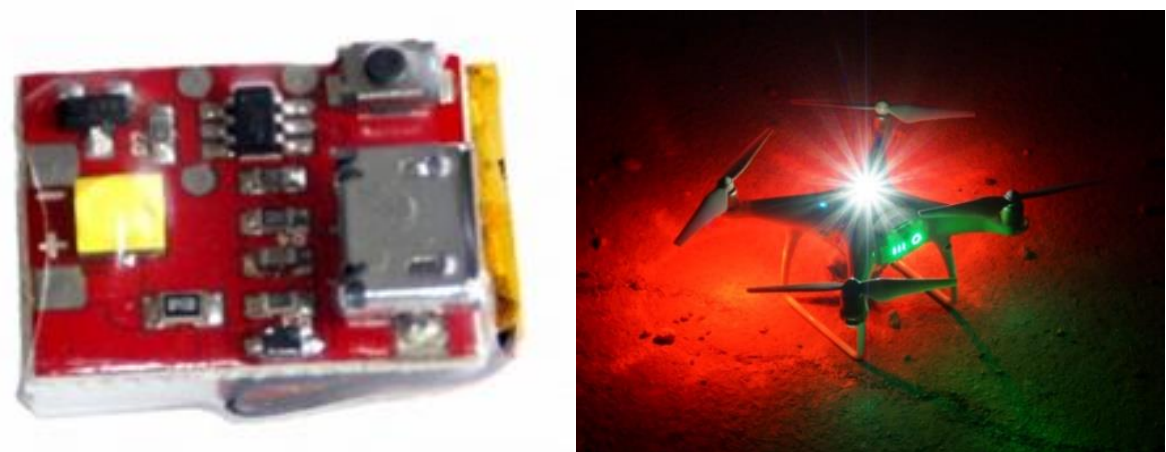

Note. Specifications available at Flytron (n.d.).

Each participant encountered the following UAS encounter scenarios:

Pass A - Hover port side of aircraft (East side of Runway 17)

Pass B - Hover starboard side of aircraft (West side of Runway 17)

Pass C - Traverse at an oblique angle on the port side of the aircraft (East of Runway 17)

Pass D - Traverse at an oblique angle on the starboard side of the aircraft (West of Runway 17)

Pass E - Control Pass, no drone flown

Researchers planned to conduct experimental flights with up to three participants each night. To provide a semi-random presentation, the first and third participants each night were presented with the encounter scenarios in order; and, the second participant was presented the encounter scenarios in reverse order.

\section{Special Wellness Procedures}

To limit the potential spread of COVID-19, the research team and participants were required to practice organizational infection prevention protocols, which included: temperature wellness checks and travel / symptom questionnaire; post-use sanitizing procedures for briefing areas and aircraft; social distancing and mandatory mask use; and, adherence to personal safety and hygiene guidance published by the university.

\section{Data Analysis}

Following each sortie, aircraft telemetry data was downloaded from the G1000 memory card in Comma-Separated Value (CSV) format. The UAS flight staff downloaded the DJI Phantom IV telemetry files using the DJI Assistant 2. 
Additional analysis was conducted using CSV View, a proprietary application designed to analyze DJI flight log files. The logs were integrated into a single MS Excel workbook. Times and dates were converted to Universal Coordinated Time (UTC), altitudes were converted to meters (m) MSL. Labels and icons were added to the dataset, before being converted into Keyhole Markup Language (KML) format using Earthpoint application software, an online tool for converting tabular coordinate data into other georeferenced formats (Earthpoint, 2021). Data analysis was performed using MS Excel and Google Earth Pro.

Qualitative data was recorded via written field notes from the principal investigator. The notes were de-identified, typed, and manually analyzed for notable comments and trends. The research team relied on this subjective, qualitative data to develop a more holistic understanding of the unanticipated problems or factors involved in this line of research.

\section{Assumptions \& Limitations}

The research team noted the following assumptions and limitations associated with this research:

- Small sample size limits study generalizability. Results should be considered exploratory and used to advise areas of future research.

- Self-reported participant demographic information was presumed accurate.

- Participants were assumed to report UAS sightings in an accurate and timely fashion.

- Participants were assumed to not have fore knowledge of the UAS maneuver sets.

- Geospatial data for aircraft and UAS were presumed to be accurate.

- Since participants were aware the study involved spotting potentiallyconflicting UAS traffic, it is likely they performed more vigilant visual scanning than during normal flight operations. UAS spotting success under normal flight conditions are likely to be lower than reported in this study.

\section{Findings \& Discussion}

The experiment was conducted from June 15, 2020 through June 18, 2020 with 10 participants ( 8 male / 2 female). All participants were qualified as at least Private Pilots (Single-Engine, Land) with most holding advanced certificates and ratings. Eighty percent of participants held a First Class FAA Medical Certificate, with two participants holding a 3rd Class FAA Medical Certificate. Additional demographic details of the participants are provided in Table 1. 


\section{Table 1}

Participant Demographics

\begin{tabular}{llllll}
\hline P\# & FAA Pilot Certificate(s) & $\begin{array}{l}\text { Medical } \\
\text { Certificate }\end{array}$ & Gender & Age Bracket & Reported Vision \\
\hline 1 & Private w/ Instrument & $1^{\text {st }}$ Class & Male & $18-29$ & $20 / 20$ \\
2 & CFI/CFII/MEI & $1^{\text {st }}$ Class & Male & $18-29$ & Unknown \\
3 & MEI & $1^{\text {st }}$ Class & Male & $18-29$ & $20 / 20$ \\
4 & CFII & $1^{\text {st }}$ Class & Male & $18-29$ & $20 / 20$ (Corrected) \\
5 & CFII & $1^{\text {st }}$ Class & Female & $18-29$ & $20 / 20$ (Corrected) \\
6 & CFII & $1^{\text {st }}$ Class & Male & $18-29$ & $20 / 20$ (Corrected) \\
7 & Commercial w/Instrument & $1^{\text {st }}$ Class & Male & $18-29$ & $20 / 20$ \\
8 & CFI & $3^{\text {rd }}$ Class & Female & $18-29$ & $20 / 20$ \\
9 & CFII & $1^{\text {st }}$ Class & Male & $18-29$ & $20 / 15$ \\
10 & Private w/ Instrument & $3^{\text {rd }}$ Class & Male & $18-29$ & $20 / 20$ \\
\hline
\end{tabular}

\section{Environmental Conditions}

Weather Conditions. All experimental flights were flown in visual meteorological conditions (VMC). A historical record of METAR reports derived from the SWO Automated Weather Observing System (AWOS) Type-3 station and archived by the Iowa State Mesonet is presented in Table 2.

Table 2

Experimental Weather Conditions

\begin{tabular}{|c|c|c|c|}
\hline $\mathrm{P \#}$ & Date/Time (L) & METAR & $\begin{array}{l}\text { Lunar } \\
\text { Illumination }\end{array}$ \\
\hline 1 & 202006152215 & $\begin{array}{l}\text { KSWO 160315Z AUTO 14005KT 10SM CLR } \\
\text { 27/17 A3012 RMK T02700170 MADISHF }\end{array}$ & $24 \%$ \\
\hline 2 & 202006152332 & $\begin{array}{l}\text { KSWO } 160430 Z \text { AUTO 13007KT 10SM CLR } \\
\text { 26/18 A3013 RMK T02600180 MADISHF }\end{array}$ & $24 \%$ \\
\hline 3 & 202006160037 & $\begin{array}{l}\text { KSWO } 160530 Z \text { AUTO 13005KT 10SM CLR } \\
\text { 25/18 A3013 RMK T02500180 MADISHF }\end{array}$ & $23 \%$ \\
\hline 4 & 202006162210 & $\begin{array}{l}\text { KSWO 170310Z AUTO 15009KT 10SM CLR } \\
\text { 27/19 A3003 RMK T02700190 MADISHF }\end{array}$ & $16 \%$ \\
\hline 5 & 202006162327 & $\begin{array}{l}\text { KSWO 170425Z AUTO 16010KT 10SM CLR } \\
\text { 26/18 A3004 RMK T02600180 MADISHF }\end{array}$ & $16 \%$ \\
\hline 6 & 202006170039 & $\begin{array}{l}\text { KSWO 170535Z AUTO 16008KT 10SM CLR } \\
\text { 26/17 A3003 RMK T02600170 MADISHF }\end{array}$ & $16 \%$ \\
\hline 7 & 202006172212 & $\begin{array}{l}\text { KSWO 180310Z AUTO 15011KT 10SM CLR } \\
\text { 28/18 A2992 RMK T02800180 MADISHF }\end{array}$ & $10 \%$ \\
\hline 8 & 202006172336 & $\begin{array}{l}\text { KSWO } 180430 Z \text { AUTO 15011KT 10SM CLR } \\
\text { 27/18 A2994 RMK T02700180 MADISHF }\end{array}$ & $10 \%$ \\
\hline 9 & 202006182157 & $\begin{array}{l}\text { KSWO 190253Z AUTO 15012KT 10SM CLR } \\
\text { 29/16 A2988 RMK AO2 SLP104 T02890156 } 52005\end{array}$ & $5 \%$ \\
\hline 10 & 202006182336 & $\begin{array}{l}\text { KSWO } 190435 Z \text { AUTO 15011KT 10SM CLR } \\
\text { 27/16 A2992 RMK T02700160 MADISHF }\end{array}$ & $5 \%$ \\
\hline
\end{tabular}

Note. Historical weather data was obtained via recorded ASOS data obtained from Iowa State University (n.d.). Lunar illumination data derived from Time and Date AS (2021). 
Background Illumination. Researchers recorded historical moon illumination levels to gauge the intensity of background lighting (see Table 2). According to Kyba, Mohar and Posch (2017), "most full Moons at mid-latitudes will produce only .05-.20 lux" (p. 1.32). According to the Encyclopedia Britannica (2012):

One lux is the amount of illumination provided when one lumen is evenly distributed over an area of one square meter. This is also equivalent to the illumination that would exist on a surface all points of which are one meter from a point source of one international candle (candela). (p. 1)

Additional measures were taken to assess the level of background illuminance originating from manmade light around the testing area. It is notable that Stillwater Regional Airport is located in proximity to an urban area occupied by an estimated 50,299 people (U.S. Census Bureau, 2019). Using a measure of luminance, a measurement of the eye's perception of reflected light, the testing area measured 1.20 (micro-candela) $\mathrm{mcd} / \mathrm{m}^{2}$ (see Figure 5). For comparison purposes, a natural starlit night measures approximately $.2-.3 \mathrm{mcd} / \mathrm{m}^{2}$; standard street lighting recommendations yield $.3-2.0 \mathrm{mcd} / \mathrm{m}^{2}$; and, a clear, suburban night sky is usually .75-14 mcd/m² (Hänel et al., 2018, Table 2). 


\section{Figure 5}

Nighttime Light Pollution Estimation Derived from Light Pollution Map (2021)

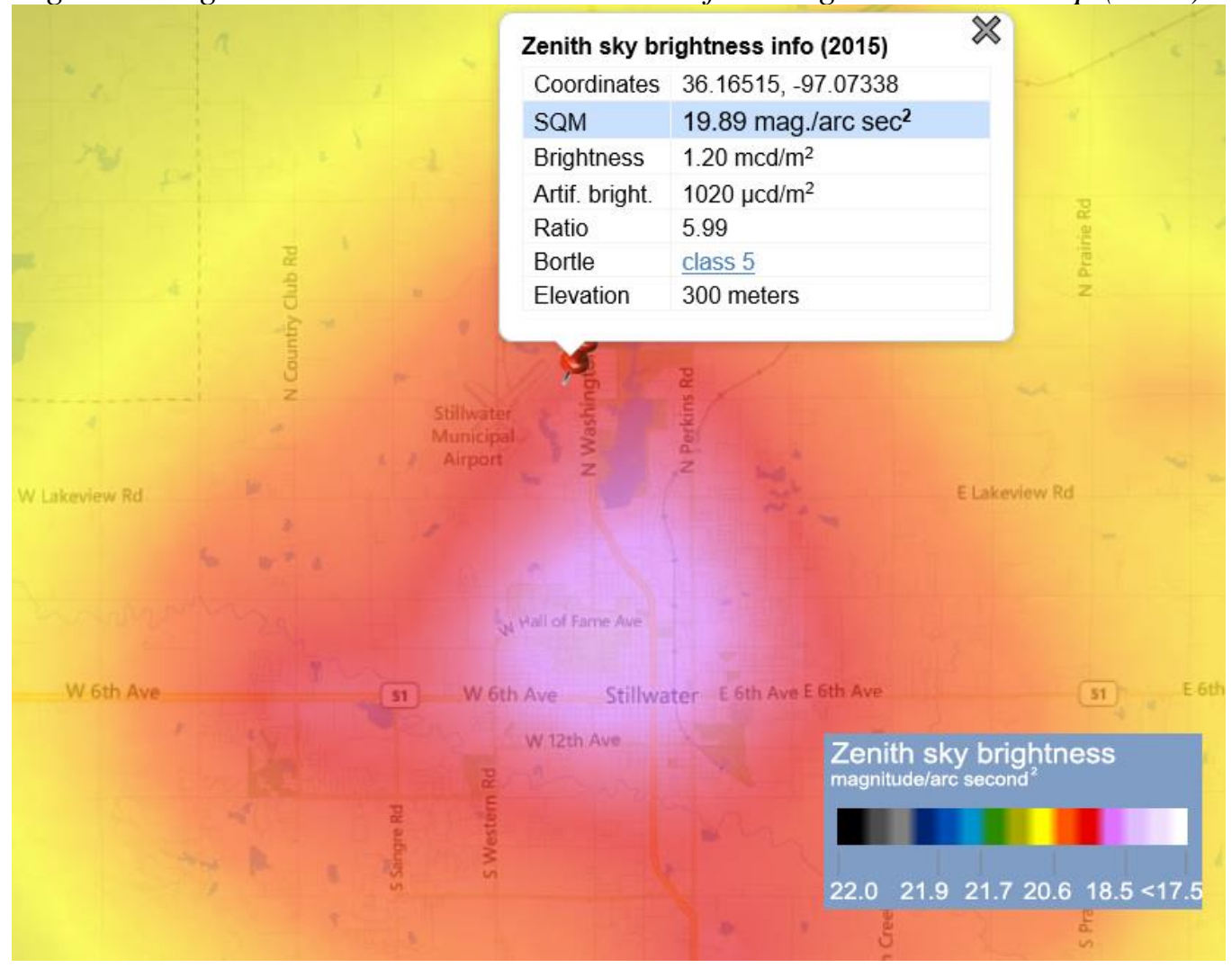

\section{UAS Sighting Results}

Cumulatively, participants spotted the UAS during a total of 12 of the available 40 passes yielding a success rate of 30 percent (see Table 3, Figure 6-7). There were no reported UAS sightings during the control pass. An overhead view of aircraft positions relative to UAS sighting locations is depicted in Figure 8. 
Table 3

UAS Sighting Ranges by Intercept Type (Feet)

\begin{tabular}{cccccc}
\hline Participant & A: Hover PS & B: Hover SS & C: Traverse PS & D: Traverse SS & E: Control \\
\hline 1 & 0 & $4383(1)^{*}$ & $5302(2)^{*}$ & 0 & 0 \\
2 & 0 & $1940(4)$ & 0 & $2235(3)$ & 0 \\
3 & 0 & 0 & 0 & $3113(5)$ & 0 \\
4 & 0 & $580(6)$ & 0 & $1404(7)$ & 0 \\
5 & $185(8)$ & 0 & 0 & 0 & 0 \\
6 & 0 & 0 & 0 & $2328(9)$ & 0 \\
7 & 0 & 0 & 0 & 0 & 0 \\
8 & $1008(12)$ & $4206(11)$ & 0 & $3424(10)$ & 0 \\
9 & 0 & 0 & $2831(13)$ & 0 & 0 \\
10 & 0 & $2316(14)$ & 0 & 0 & 0 \\
\hline
\end{tabular}

Note. Successful UAS sightings are numbered in parenthesis to facilitate data comparison and discussion. *Indicates sighting was possible, but unconfirmed; data was removed from success metrics.

\section{Figure 6}

Profile View of UAS Sightings by Range (ft) \& Altitude (ft) Relative to Aircraft by UAS Pass Type

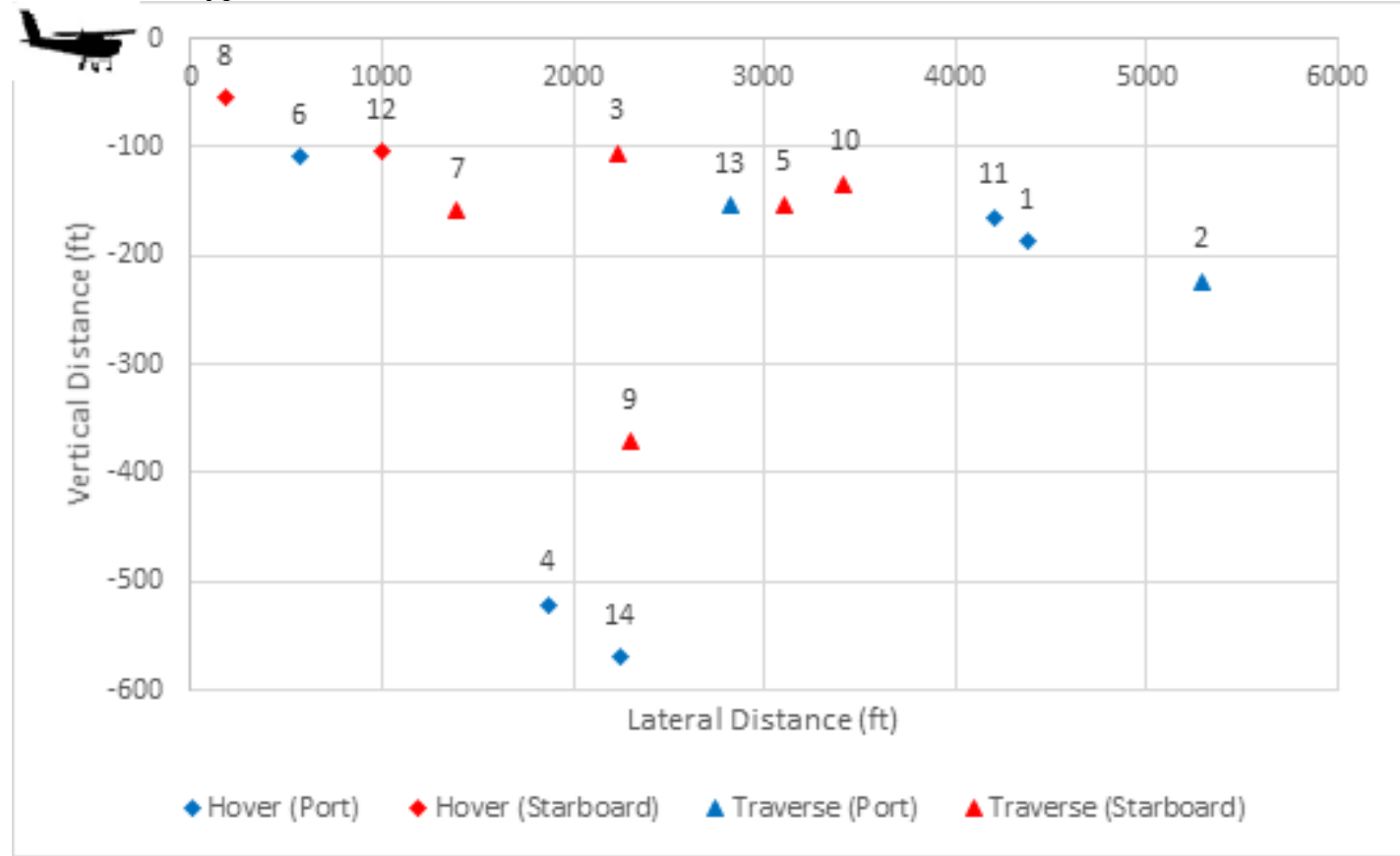

Note. UAS sightings are labeled with sighting number (see Table 3). 


\section{Figure 7}

Profile View of UAS Sightings by Range (ft) \& Altitude (ft) Relative to Aircraft Position along Glideslope

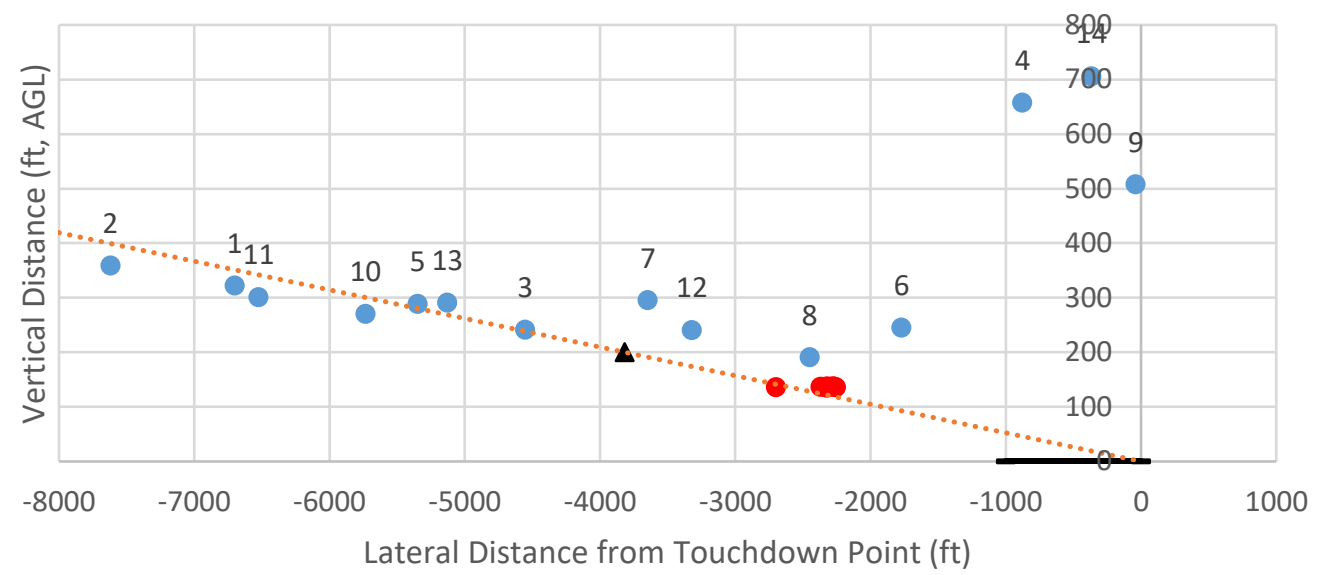

- AC Position

- UAS Runway

A MAP

Glideslope

Note. Aircraft positions are labeled with sighting number (see Table 3). Missed approach point and initial runway segment to touchdown point also depicted. 


\section{Figure 8}

Top-Down View of Aircraft and UAS Positions at Time of Sightings Presented using Google Earth Pro

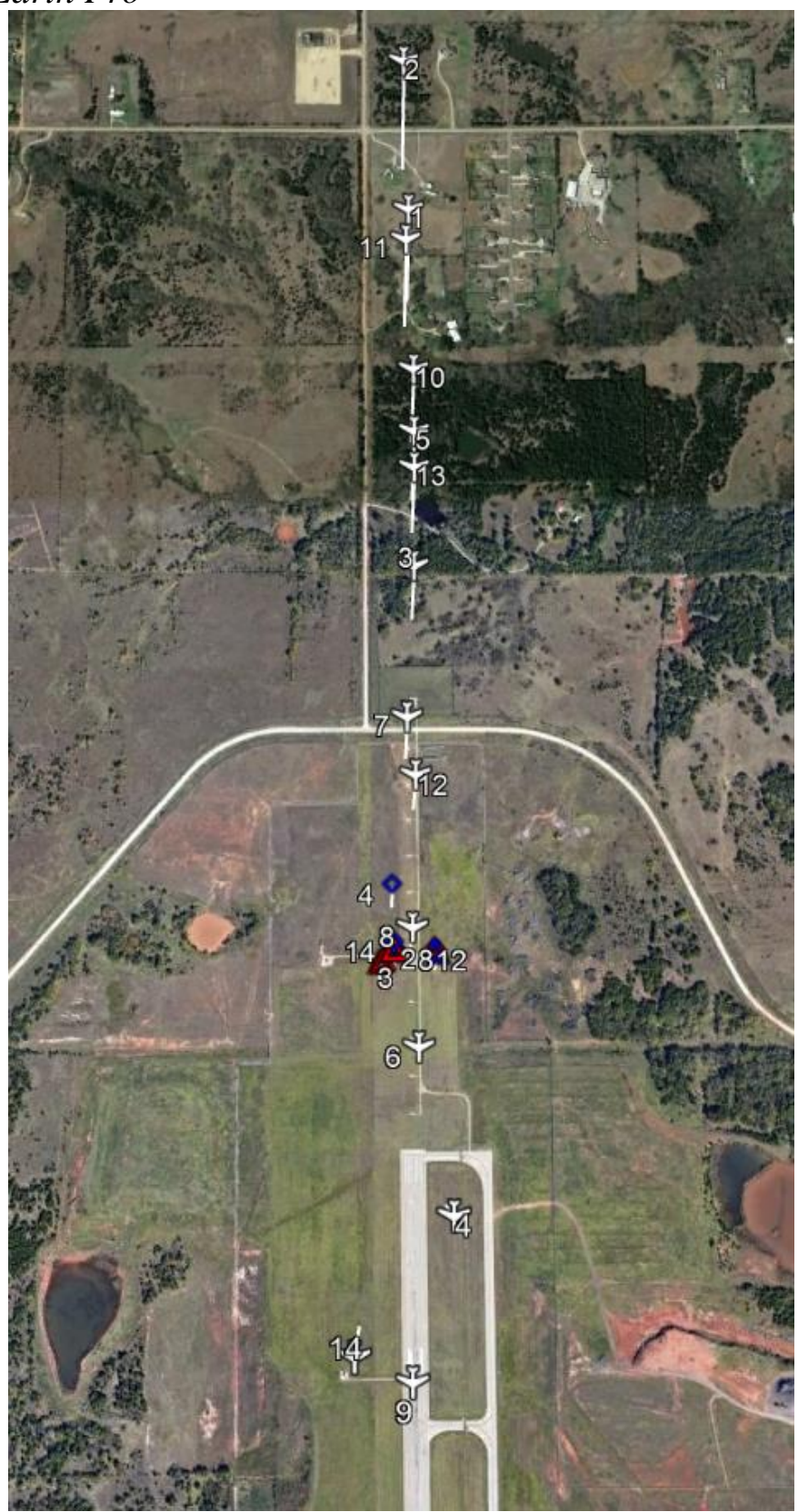

Note. Both aircraft position and UAS position are labeled with sighting number (see Table 3). UAS icon and color correspond to pass type using same schematic as Figure 6. 
Visual data. Several images were taken by the safety pilot using a digital camera to provide a visual record of a sample of the UAS encounters. A selection of these images are presented in Figures 9-11. Figure 11 also includes corresponding telemetry data indicating the positions of both the aircraft and UAS at the time the participant reported a successful sighting.

\section{Figure 9}

Image Taken from Aircraft Starboard Side during Participant 3 's First Pass with Target sUAS

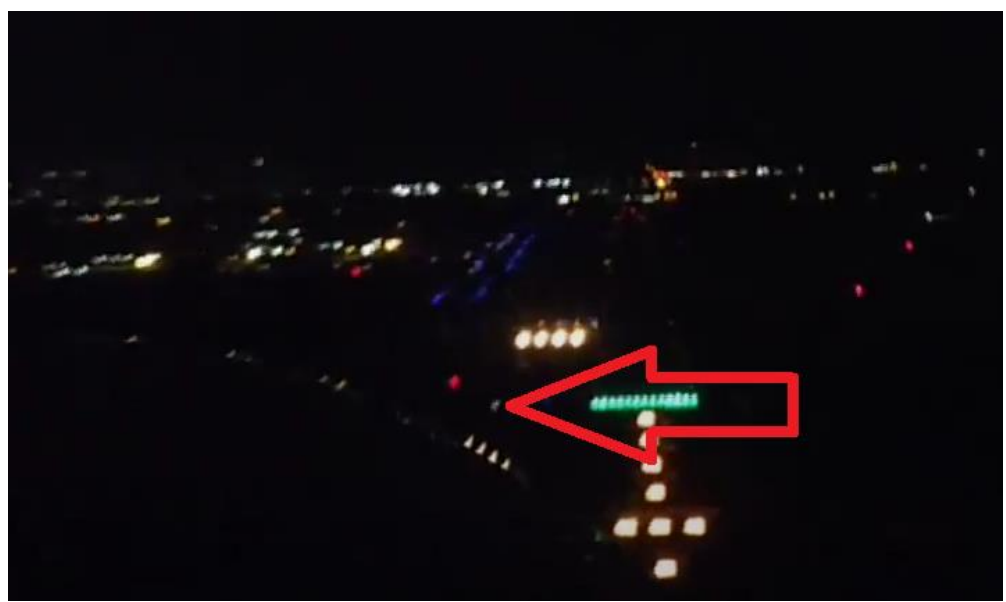

Note. Strobe light indicated by red arrow. (UAS hovering, portside of aircraft).

\section{Figure 10}

Image Taken from Aircraft Starboard Side during Participant 3's Second Pass with Target sUAS

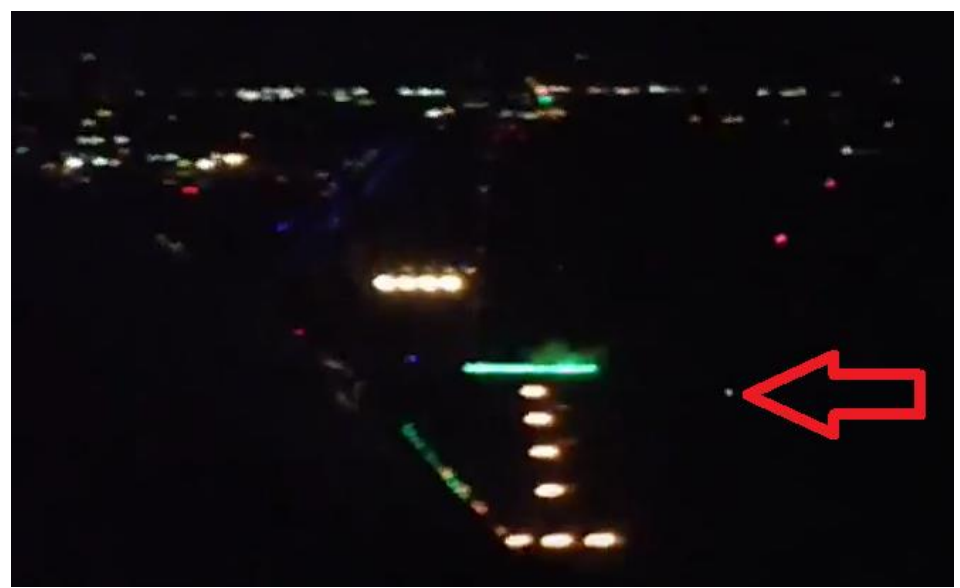

Note. sUAS indicated by red arrow. (UAS hovering starboard side of aircraft). 


\section{Figure 11}

Image Taken from Aircraft Starboard Side during Participant 8's Fifth Pass with Target Indicated by Red Arrow [TOP]. Aircraft and UAS Telemetry during Participant 8's Fifth Pass. [BOTTOM]

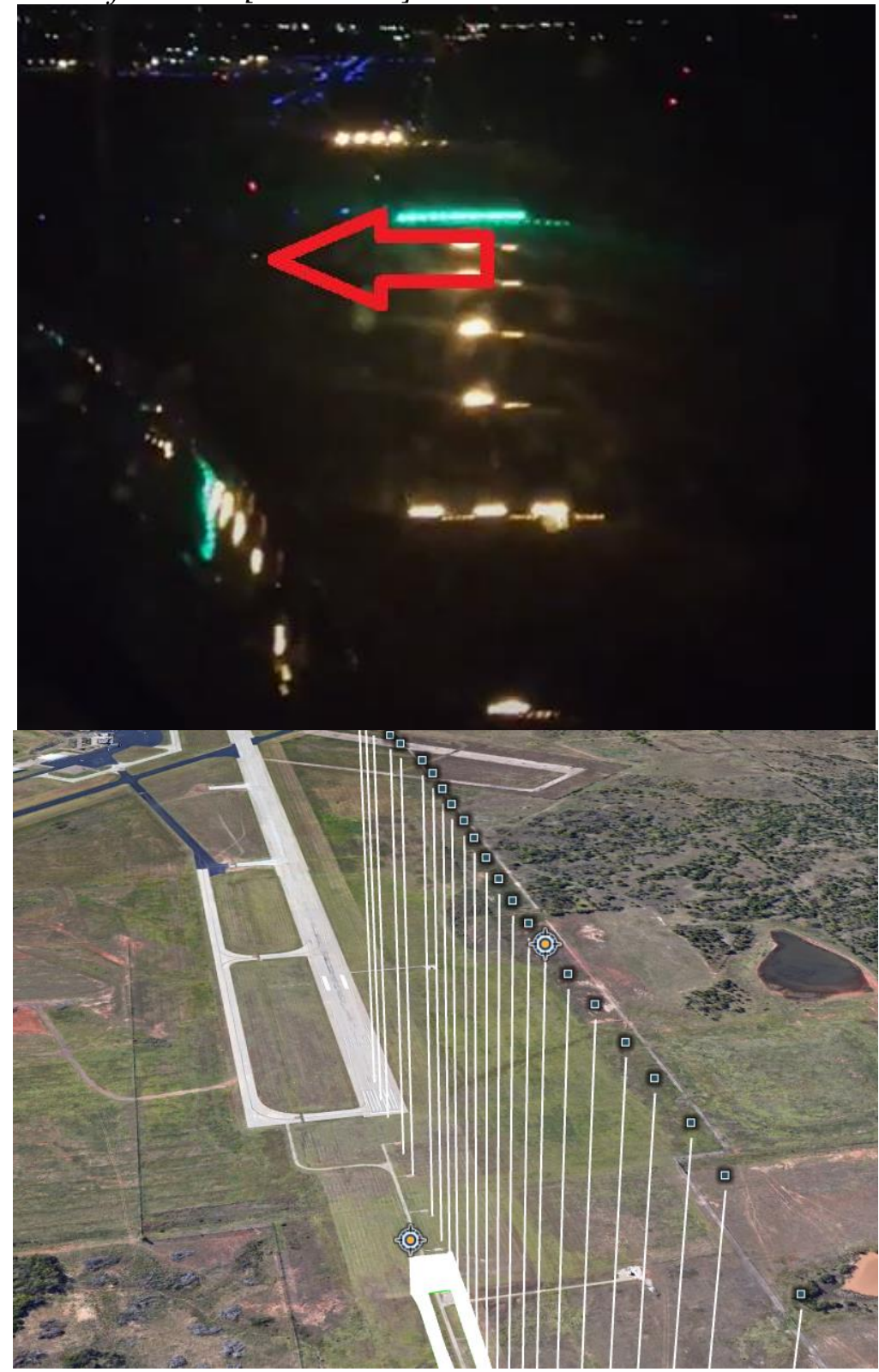

Note. Relative position between aircraft and UAS at time of sighting indicated by the two reticule icons. (UAS was hovering, portside of aircraft).

Data adjustment \& resolution. Participant 1 indicated spotting the sUAS during the portside hovering (A) and port traversing (C) passes; and, the 
participant did not indicate spotting the sUAS during the control pass when no sUAS was inflight. Following the completion of the experiment, the participant questioned the validity of the sightings, indicating that they were likely "porch lights" or other light pollution not associated with the experiment. It is difficult to ascertain the validity of these participant's sightings, as they represented the furthest sighting ranges of all participants. The research team elected to retain and present the data for context, but excluded these sightings from reported success metrics.

Spotting metrics based on moving vs. static UAS. Participants had equal success spotting both the moving and hovering UAS, with an overall success rate of 30 percent $(n=6)$. Hovering UAS were spotted at an average range of 1,705.8 feet and a median of 1,474 feet. Moving UAS were spotted at an average range of 2,555.8 feet and a median of 2,579.5 feet.

This was somewhat expected, as moving objects are generally easier to spot than static objects. According to the Federal Aviation Administration (2016c) Advisory Circular 90-48D:

Peripheral vision can be most useful in spotting collision threats from other aircraft. Each time a scan is stopped and the eyes are refocused, the peripheral vision takes on more importance because it is through this element that movement is detected. Apparent movement is almost always the first perception of a collision threat, and probably the most important, because it is the discovery of a threat that triggers the events leading to proper evasive action ... Visual search at night depends almost entirely on peripheral vision. This is due in part to the night blind spot that involves an area between 5 and 10 degrees wide in the center of the visual field. (p. 3)

Spotting metrics based on lateral UAS position. Overall, participants were less successful spotting the UAS when it was on the port side of the aircraft. Participants successfully spotted the UAS during only $20 \%$ of hovering passes and $10 \%$ of traversing passes, when the UAS was oriented on the port side of the aircraft. Conversely, the participants spotted the UAS during $40 \%$ of hovering passes and $50 \%$ of traversing passes, when the UAS was oriented on the starboard side of the aircraft. This was a somewhat counter-intuitive finding, as it would be generally expected that objects on the pilot's side of the aircraft (port side) would be more likely to be spotted due to the pilot's relatively unobstructed view out the port-side window. One possible explanation for the lower spotting rate for port side targets is that they are being camouflaged or otherwise lost in the bright PAPI lighting. Due to the airport and runway selection, airport taxiway and ramp lighting also cluttered the port side view, potentially masking the UAS. On the 
starboard side of the aircraft, visibility seemed to be improved due to the lack of ambient lighting, approach lighting, or other lighting sources. This finding is supported by FAA (2016c) guidance, which states: "conflicting ground lights at night increase the difficulty of detecting other aircraft" (p. 3). These conditions are readily discernable in Figures 9 and 11. The area on the starboard side of the aircraft (immediately west of Runway 17) was particularly dark creating an ideal area to spot the contrasting strobe lighting of the UAS (see Figure 10).

UAS distance estimations. After successfully spotting a UAS, participants were asked to estimate the distance from the aircraft to the UAS. Participants provided distance estimates following 9 of the 12 successful UAS sightings $(n=$ $75 \%$ ). Participant distance estimates are presented in Table 4 following the actual distance measurements. While most participant estimates were provided in feet, two distance estimates were given in fractions of a nautical mile, which were converted to feet. In seven of nine recorded estimations, participants underestimated the true distance to the sUAS by a mean of 883 feet, and a median of 940 feet.

\section{Table 4}

UAS Sighting Ranges by Intercept Type with Participant Distance Estimates (Feet)

\begin{tabular}{ccccc}
\hline Participant & A: Hover PS & B: Hover SS & C: Traverse PS & D: Traverse SS \\
\hline 1 & 0 & $4383(\mathrm{~N})^{*}$ & $5302(\mathrm{~N})^{*}$ & 0 \\
2 & 0 & $1940(1000)$ & 0 & $2235(700)$ \\
3 & 0 & 0 & 0 & $3113(1000)$ \\
4 & 0 & $580(1000)$ & 0 & $1404(1000)$ \\
5 & $185(\mathrm{~N})$ & 0 & 0 & 0 \\
6 & 0 & 0 & 0 & $2328(1520)$ \\
7 & 0 & 0 & 0 & 0 \\
8 & $1008(50)$ & $4206(\mathrm{~N})$ & 0 & $3424(\mathrm{~N})$ \\
9 & 0 & 0 & $2831(3040)$ & 0 \\
10 & 0 & $2316(500)$ & 0 & 0 \\
\hline
\end{tabular}

Note. Numbers in parenthesis indicate pilot distance estimates to spotted UAS in feet. An "N" indicates the participant was non-responsive or did not provide a distance estimate. *Indicates sighting was possible, but unconfirmed.

Evasive action potential. Of the 12 successful sightings, four (25\%) occurred after the aircraft passed the UAS position. While these were still calculated as successful sightings, these participants would not have been successful in identifying the UAS in time to prevent a potential collision. According to the FAA (2016c), "Research has shown that the average person has a reaction time of 12.5 seconds" (p. 2). When applying this standard based on the speed of the aircraft at the time of each UAS sighting and assuming a static UAS 
position, in only $50 \%$ of successful UAS sightings $(n=6)$ did pilots have adequate time to initiate evasive action to avoid a collision (see Table 5).

\section{Table 5}

Time to Impact at Time of Sighting Based on Static UAS at Measured Aircraft Speed (Seconds)

\begin{tabular}{ccccc}
\hline Participant & A: Hover PS & B: Hover SS & C: Traverse PS & D: Traverse SS \\
\hline 1 & 0 & $32.0(1)^{*}$ & $37.6(2)^{*}$ & 0 \\
2 & 0 & $18.3(4)^{* *}$ & 0 & $15.7(3)$ \\
3 & 0 & 0 & 0 & $20.2(5)$ \\
4 & 0 & $3.8(6)^{* *}$ & 0 & $10.6(7)$ \\
5 & $1.5(8)$ & 0 & 0 & 0 \\
6 & 0 & 0 & 0 & $17.6(9)^{* *}$ \\
7 & 0 & 0 & 0 & 0 \\
8 & $8.2(12)$ & $31.1(11)$ & 0 & $26.5(10)$ \\
9 & 0 & 0 & $18.5(13)$ & 0 \\
10 & 0 & $20.1(14)^{* *}$ & 0 & 0 \\
\hline
\end{tabular}

Note. Successful UAS sightings are numbered in parenthesis to facilitate data comparison and discussion (see Table 3). Sightings presented in red text would likely have collided with UAS, based on 12.5 second reaction standard (FAA, 2016c). *Indicates sighting was possible, but unconfirmed. $* *$ Sighting occurred after aircraft passed UAS position, therefore collision avoidance was impossible.

\section{Additional Observations}

Confusion with Airport Lighting or Approach Lighting Systems. The researchers recorded feedback comments during 10 of the 12 successful sightings, regarding participants' abilities to discern a UAS from the airport or approach lighting systems. Three of the 10 comments indicated that participants initially believed the UAS was actually a part of the airport or approach lighting. Participant \#8 reported observing “. . . only the light, which at first appeared to be a part of the approach end runway lighting system." Participant \#3 similarly stated, "Initially I confused the light with the approach end lights." The remaining comments indicated that participants were either not confused by the UAS lighting or discerned that the UAS lights did not appear to be a part of the airport environment. When coupled with the aforementioned sighting validity issues regarding Participant \#1, the research team suggests that lighting confusion may still present a potential problem for some pilots.

UAS Orientation. One possible issue that was identified during the course of the study was the orientation of the UAS relative to the aircraft. When performing a static hover - particularly in elevated winds - the UAS will sometimes enter a shallow pitch against the wind to maintain position. Since aircraft generally land into the wind, this could orient a UAS flying near the 
approach end of a runway as tilted towards the runway. Since it is generally common practice to position required night lighting systems to the top of the UAS, this could possibly result in the UAS lighting becoming somewhat occluded as the UAS tilts into the wind-facing away from approaching aircraft - to maintain position.

According to the FAA (2016b) Human vision is subject to several additional complications when operating during nighttime conditions, including:

Mesopic Vision. Generally experienced during civil twilight, as well as during periods of lunar illumination, Mesopic vision results in a continual degradation of visual acuity in the cones corresponding to the drop in ambient light (FAA, 2016b).

Scotopic Vision. Scotopic vision is characterized by a lack of detail recognition to small objects, loss of color vision, and the development of a night blind spot that occurs during periods of low-lighting (FAA, 2016b).

Night Blind Spot. Temporary blind spot created in the central, foveal view of the eye, as rods in periphery become the primary visual sensor during low-light conditions (FAA, 2016b).

Dark Adaptation. Process by which the eye adjusts to darker environment by increasing the light sensitivity of the rods (FAA, 2016b).

While several of these conditions were likely experienced by the participants, there were no qualitative comments that specifically identified this issues.

\section{Visual Detection Rate}

\section{Conclusions}

The overall visual detection rate for successful sightings of sUAS while on final approach during nighttime conditions was found to be $30 \%$. The data did not show disparity in the spotting rates for sUAS in motion or static positions, however, moving UAS were spotted at a further distance than static sUAS. Participants showed slightly elevated success rates in spotting sUAS oriented on the starboard side of the aircraft vs. the port side. The researchers believe this disparity is likely due to the presence of airport lighting and approach lighting systems oriented on that side of the approach view during this experiment.

\section{Effect of Airport Approach Lighting}

While $70 \%$ of participant comments indicated they were able to effectively discern the sUAS lighting from airport or approach lighting systems, at least $30 \%$ of participants indicated difficulty making such a distinction. The researchers suspect that the participant's fore knowledge of the purpose of the experiment may have artificially inflated the recognition of the sUAS. The researchers further assert that under normal flight conditions, it would be much more unlikely that pilots would be able to discern a UAS from either background 
lighting, airport lighting, or approach lighting. Additional research is recommended in this area.

\section{Ability to Evade sUAS Encountered During Nighttime Approach}

Participants were only able to spot the sUAS during nighttime approach conditions on 12 of the available 40 passes, yielding a success rate of $30 \%$. When collision avoidance and evasion is considered in the experimental success criteria, however, this metric drops to $15 \%(n=4)$ of the sample. Additionally, the participant's knowledge of the experimental conditions likely enhanced their external scanning vigilance, indicating that even this finding may be inflated. The research team asserts that under normal flying conditions, a pilot flying an approach during nighttime conditions is unlikely to spot a sUAS in time to perform a successful evasive maneuver. Moreover, this experiment utilized a relatively slow general aviation aircraft as a testbed, meaning that a faster-moving aircraft crew would be even less likely to successfully evade a sUAS during a nighttime approach due to the compressed response timeline.

\section{Recommendations}

The research team recommends additional study of nighttime UAS collision mitigation measures, including the use of electronic detection and tracking equipment, such as Remote Identification. When performing night operations - particularly in proximity to airports - Remote Pilots should maintain vigilant awareness of aircraft through the use of diligent visual scanning, monitoring of Common Traffic Advisory Frequencies, and use of ADS-B (In) traffic awareness systems. 


\section{References}

Aratani, L. (2019). Did a pair of drones interfere with flights at Newark Airport, or was it something else? Washington Post. Retrieved from https://www.washingtonpost.com/transportation/2019/01/23/did-pairdrones-interfere-with-flights-newark-airport-or-was-it-something-else/

City of Stillwater. (2020). Airport projects. Retrieved from http://stillwater.org/ page/home/government/current-projects/airport-projects

Dolgov, I. (2016). Moving towards unmanned aircraft systems integration into the national airspace system: Evaluating visual observers' imminent collision anticipation during day, dusk, and night sUAS operations. International Journal of Aviation Sciences, 1(1).

Earthpoint. (2021). Earthpoint: Tools for Google earth [Website]. Retrieved from https://www.earthpoint.us/Default.aspx

Encyclopedia Britannica. (2012). Lux. Retrieved from https://www.britannica.com/science/lux

Federal Aviation Administration. (2016a). Operation and certification of small unmanned aircraft systems. Retrieved from https://www.faa.gov/uas/ media/RIN_2120-AJ60_Clean_Signed.pdf

Federal Aviation Administration. (2016b). Pilot's handbook of aeronautical knowledge [FAA-H-8083-25B]. Retrieved from https://www.faa.gov/ regulations_policies/handbooks_manuals/aviation/phak/media/pilot_handb ook.pdf

Federal Aviation Administration. (2016c). Pilots role in collision avoidance [advisory circular]. Author. Retrieved from https://www.faa.gov/ documentLibrary/media/Advisory_Circular/AC_90-48D_CHG_1.pdf

Federal Aviation Administration. (2020a). Chart supplements. Retrieved from https://www.faa.gov/air_traffic/flight_info/aeronav/digital_products/dafd/s earch/

Federal Aviation Administration. (2020b). Lighting systems - Medium approach light system with runway alignment indicator lights (MALSR). Retrieved from https://www.faa.gov/about/office_org/headquarters_offices/ ato/service_units/techops/navservices/lsg/malsr/

Federal Aviation Administration. (2020c). UAS sighting reports. Retrieved from https://www.faa.gov/uas/resources/public_records/uas_sightings_report/

Flytron. (n.d.). Flytron - Strobon Cree [website]. Retrieved from https://www.readymaderc.com/products/details/flytron-strobon-creewhite\#features-tab

Hänel, A., Posch, T., Ribas, S. J., Aubé, M., Duriscoe, D., Jechow, A., . . Kyba, C. C. M. (2018). Measuring night sky brightness: Methods and challenges. Journal of Quantitative Spectroscopy \& Radiative Transfer, 205, 278-290. doi:10.1016/j.jqsrt.2017.09.008 
Iowa State University. (n.d.). Iowa environmental MESONET [website/database]. Retrieved from https://mesonet.agron.iastate.edu/

Kephart., R. J., \& Braasch, M. S. (2010). See-and-avoid comparison of performance in manned and remotely piloted aircraft. IEEE Aerospace and Electronic Systems Magazine, 25(5), 36-42. doi:10.1109/MAES.2010.5486540.

Kyba, C. M., Mohar, A. \& Posch, T. (2017). How bright is the moonlight. Astronomy \& Geophysics, 58(1), 1.31-1.32. https://doi.org/10.1093/ astrogeo/atx 025

Law, T. (2019). New Jersey airport brought to a halt after multiple flights report spotting a drone. Time. Retrieved from https://time.com/5510249/newarkairport-drone/

Light Pollution Map. (2021). Light pollution map [website/application]. Retrieved from https://www.lightpollutionmap.info/

LiveATC. (2019). Drone on final to EWR [Audio Recording]. Author. Retrieved from https://www.liveatc.net/recordings.php

Loffi, J. M., Wallace, R. J., Jacobs, J. D. \& Dunlap, J. C. (2016). Seeing the threat: Pilot visual detection of unmanned aircraft systems in visual meteorological conditions. International Journal of Aviation, Aeronautics, and Aerospace, 3(3). http://commons.erau.edu/ijaaa/vol3/iss3/13/

Maddocks, J. \& Griffitt, G. (2015). Test report: Qualitative evaluation of unmanned aircraft visibility during agricultural flight operations. Avian. Retrieved from https://www.coagav.org/resources/Documents/TBYL\% 20Visibility\%20Flight\%20Test\%20Report_FINAL.pdf

Operation of small unmanned aircraft systems over people, 48 (10), 4314, Fed. Reg. (January 15, 2021) to be codified at 14 C.F.R. Parts 11, 21, 43, \& 107.

Schmidt, B., \& Vance, A. (2020). DJI won the drone wars, and now it's paying the price. Bloomberg Business. Retrieved from https://www.bloomberg.com/news/features/2020-03-26/dji-s-dronesupremacy-comes-at-a-price?utm_source=pocket-newtab

Shepardson, D. (2019). FAA details impact of drone sightings on Newark airport. Reuters. Retrieved from https://www.reuters.com/article/us-usadrones/faa-details-impact-of-drone-sightings-on-newark-airportidUSKCN1PH243

Stevenson, J. D., O’Young, S., Rolland, L. (2015). Enhancing the visibility of small unmanned aerial vehicles. Procedia Manufacturing, 3, 944-951. 0.1016/j.promfg.2015.07.143

Time and Date AS. (2021). Moon phases visualized: Where is the Moon? Retrieved from https://www.timeanddate.com/astronomy/moon/ location.html 
U.S. Census Bureau. (2019). Quick facts: Stillwater, Oklahoma. Retrieved from https://www.census.gov/quickfacts/stillwatercityoklahoma?

United States Air Force. (1977). ADS strobe light evaluation [Technical Report ASD-TR-77-33). Retrieved from https://apps.dtic.mil/dtic/ tr/fulltext/u2/a045533.pdf

Wallace, R. J., Loffi, J. M., Vance, S. M., Jacob, J. D., Dunlap, J. C., \& Mitchell, T. A. (2018). Pilot visual detection of sUAS equipped with strobe lighting. Journal of Aviation Technology \& Engineering, 7(2), 57-66. https://doi.org/10.7771/2159-6670.1177

Wallace, R. J., Vance, S. M., Loffi, J. M., Jacob, J. D., Dunlap, J. C., Mitchell, T. A., Thomas, R. L., \& Seabrook, W. R. (2019). Cleared to land: Pilot visual detection of small unmanned aircraft during final approach. International Journal of Aviation, Aeronautics, and Aerospace, 6(5). Retrieved from https://commons.erau.edu/ijaaa/vol6/iss5/12

Williams, K. W. \& Gildea, K. M. (2014). A review of research related to unmanned aircraft system visual observers [Report: DOT/FAA/AM-14/9). Retrieved from https://www.faa.gov/data_research/research/ med_humanfacs/oamtechreports/2010s/media/201409.pdf 